\title{
FAKE NEWS E AGRESSÕES VIRTUAIS: O PAPEL DAS OUVIDORIAS LEGISLATIVAS
}

\section{Douglas Stravos Diniz Moreno'}

\begin{abstract}
Resumo
Este estudo investiga o papel das Ouvidorias Legislativas no combate às fake news e no tratamento das agressões pelos meios eletrônicos que são produzidas contra o Parlamento e seus agentes públicos. As Ouvidorias representam um modelo bem-sucedido da moderna Administração Pública inspirada nos ideais de boa governança, participação e controle social. Através desse canal, o cidadão sugere, critica, elogia, obtém informações, consegue respostas oficiais às suas demandas no prazo legal; e o mais importante: elas estão aptas juridicamente a produzir seus efeitos. Essa nova condição se distingue da relação informal entre a sociedade e o Poder Público, onde há grande possibilidade dos dados obtidos se tornarem notícias falsas ou fake news, por se basearem em fontes inseguras. Por sua vez, o uso do canal da Ouvidoria deve obedecer aos critérios de urbanidade e boa-fé por parte do cidadão, não sendo desejável a realização de reclamações e denúncias ofensivas que venham a configurar crime contra a honra nas suas várias modalidades. Mas o que a Ouvidoria Legislativa deve fazer quando ocorrem essas irregularidades no manuseio da informação e na realização de manifestações ofensivas?
\end{abstract}

Palavras-chave: Ouvidorias legislativas. Fake news. Agressões virtuais. Crime cibernético. Lei de Acesso à Informação. Código de Defesa do Usuário de Serviço Público.

DOI:10.37814/2594-5068.2020v3.p263-275

1 Procurador Legislativo e Ouvidor Executivo da Assembleia Legislativa do Estado de Pernambuco. Mestre em Direito Administrativo. Master of Administrative Law (LLM) pela Victoria University of Wellington na Nova Zelândia e ex-bolsista do programa australiano (Professional Development Scholarship Award), com atuação no Ombudsman SA, em Adelaide, Austrália. Conferencista na UNAFEI (United Nations Asia and Far East Institute) em Tóquio, Japão. Especialista em Direito Público e Privado pela Faculdade de Direito de Lisboa. Bacharel em Direito pela UFPE. 


\begin{abstract}
This study investigates the role of the Legislative Ombudsman's Office in combating fake news and the treatment of cyber-crime. Ombudsmen represent successful models of good governance practices in the public administration, inspired by the ideals of public participation and social control. Through this channel, citizens are engaged to suggests, praise, criticize, obtain information and answers from de government to their questions in a legal deadline; and the most important: they are legally capable to bind and to be enforced. This new scenario differs from the informal mode of interaction between society and government where information obtained is more vulnerable to be transformed in fake news due to the absence of reliable sources. In turn, citizens must comply with principles of civility and good faith when making complaints against government as it is not acceptable behaviours that can be considered criminal offenses. However, what is the role of the Ombudsmen when official information is distorted and criminal offenses are made?
\end{abstract}

Keywords: Legislative Ombudsman's Office. Fake news. Virtual attacks. Cyber-crime. Information Access Law. Public Service User Defense Code. 


\section{INTRODUÇÃO}

Este estudo visa explorar o papel das Ouvidorias Legislativas no tratamento das notícias falsas ou fake news, bem como das agressões sob o formato de manifestações que porventura sejam realizadas contra o Parlamento e seus membros.

As Ouvidorias Legislativas, como espécie de Ouvidorias Públicas, possuem atribuições definidas em normativos próprios, com observância das diretrizes contidas na Lei 13.460/2017 (Código de Defesa do Usuário do Serviço Público) e na Lei 12.527/2011, conhecida como Lei de Acesso à Informação (LAI), sendo consideradas como canais de comunicação qualificados entre a sociedade e o Poder Legislativo.

Em que pese existirem os Serviços de Informação ao Cidadão em alguns órgãos do Poder Legislativo que gerenciam os pedidos de informação formulados à luz da Lei de Acesso à Informação, tem sido uma tendência natural a instalação de Ouvidorias Legislativas que acumulam essa atividade prevista na LAI, com o recebimento das manifestações descritas na Lei 13.460/2017, a exemplo das reclamações e denúncias, para que dentro do prazo legal previsto nesses diplomas o cidadão obtenha uma resposta da instituição.

Sem embargo, o presente trabalho irá concentrar as questões aqui tratadas sob o ângulo das Ouvidorias Legislativas que acumulam as duas atividades e que estão instaladas em alguns órgãos do Poder Legislativo, não englobando as dos Tribunais de Contas.

O tema revela-se oportuno para debate, uma vez que, nas últimas eleições realizadas no Brasil, as redes sociais exerceram papel fundamental no debate político e uma verdadeira guerra de notícias falsas e agressões virtuais se instalou nas plataformas digitais, produzindo efeitos jamais experimentados, não se sabendo o que era verdadeiro ou manipulado.

A velocidade da propagação de notícias, sejam elas verdadeiras ou falsas, na internet revelou-se um grande desafio. A TV, o rádio, o jornal impresso deixaram de ser a referência única ou mais relevante de informação. O que circulou nas redes sociais passou a ser o novo termômetro do mundo político e a pauta principal na formação da opinião pública. O risco é que muitas vezes essas informações são disseminadas com base em fontes desautorizadas e não seguras.

Considerando que as Ouvidorias Legislativas atuam como gestoras das informações e canal qualificado das manifestações realizadas pela sociedade, o que será desenvolvido neste estudo será a análise das linhas divisórias de competência entre as Ouvidorias Legislativas e os setores de Comunicação e Procuradorias dessas instituições públicas quando estão diante de fake news, assim como nas manifestações ofensivas envolvendo o Parlamento e seus agentes, que tenham reflexos na esfera penal e civil.

\section{FAKE NEWS E AS OUVIDORIAS LEGISLATIVAS}

\subsection{A Informação Obtida Através das Ouvidoria Legislativas como Fonte Legal}

ALei Federal 13.460/2017 (Código de Defesa do Usuário do Serviço Público) e a Lei 12.527/2011, 
conhecida como Lei de Acesso à Informação (LAI), consolidaram os modelos de Ouvidorias Públicas e Serviços de Informação ao Cidadão (SIC) como canais de contato qualificados que a sociedade possui para obter do Poder Público um posicionamento formal sobre uma manifestação realizada ou um pedido de acesso à informação.

É importante ressaltar, todavia, que as Ouvidorias Legislativas não são órgãos responsáveis pelo conteúdo técnico da informação que é entregue ao cidadão. Essas Ouvidorias monitoram o prazo de resposta e podem até avaliar se a resposta que foi dada pelo departamento competente corresponde ao pedido ou se é suficiente, devolvendo ao setor para que ela seja complementada, mas elas não estão aptas a informar ou responder sobre aspectos técnicos que não detêm competência, salvo quando se tratar de matéria inerente ao próprio departamento ou que ela possa deliberar a respeito.

As Ouvidorias Legislativas, por exemplo, devem examinar se os critérios legais estão preenchidos para que o pedido de acesso à informação ou manifestação possa ser encaminhado internamente para resposta, entretanto não realizam uma apreciação se os dados técnicos estão certos ou errados nem investigam denúncias que foram protocoladas, nem tampouco podem substituir o órgão ou agente público titular da informação que se persegue.

Desse modo, a informação que é considerada oficial é aquela veiculada através dos canais de acesso colocados à disposição pelas Ouvidorias Legislativas e entregues ao cidadão por esse departamento, mas não necessariamente a que é produzida por elas.

Com fundamento na legislação vigente que consolidou as Ouvidorias no cenário da Administração Pública, para que uma informação ou resposta tenha o status oficial, ela precisa ter sido disponibilizada ao cidadão por meio dos mecanismos de transparência ativa e passiva (Ouvidorias e Serviços de Informação ao Cidadão). Esta reflexão é necessária, uma vez que, inadvertidamente, se uma informação ou resposta é dada diretamente ao cidadão por agentes públicos da instituição, sem a supervisão da Ouvidoria, há uma alteração relevante no seu status.

De maneira didática, a transparência passiva ocorre quando o cidadão provoca a instituição a emitir informação ou resposta sobre o seu pedido, pois a informação que procura não está ao seu alcance através dos mecanismos de transparência ativa, como é o Portal da Transparência. Isso porque a Lei de Acesso à Informação estabeleceu expressamente que é este o caminho formal para que o cidadão possa interagir formalmente com o órgão público, existindo requisitos necessários, limitações e prerrogativas estabelecidas em lei.

A imprescindibilidade da Ouvidoria na transparência passiva então se revela evidente dentro do novo contexto legal, pois caso a resposta ou informação pudesse ser recebida diretamente dos órgãos internos ou dos agentes públicos da instituição, sem passar pela Ouvidoria, não haveria a necessidade da regulação em comento. Se este disciplinamento ocorre é porque a passagem da manifestação pela Ouvidoria com a obtenção de resposta tem um significado relevante.

Por esse motivo, por exemplo, se alguém objetiva criticar o funcionamento de algum Parlamento ou da atividade exercida pelos seus membros e o faz com base em alguma fonte, há de ser indagado se ela foi obtida através dos mecanismos de transparência ativa ou passiva.

Se por acaso alguma informação ou resposta é obtida diretamente dos agentes públicos e departamentos que integram o Poder Legislativo, sem passar pelo canal de comunicação que é a 
Ouvidoria, essa não tem o condão de vincular a instituição em si, responsabilizando-se pela sua integridade e/ou por seu mérito tão somente aquele(a) que a forneceu, salvo se aquele(a) que a disponibiliza diretamente está atuando como representante legal daquele órgão do Poder Legislativo, função naturalmente exercida pelos seus presidentes ou na hipótese, ainda existente, de não haver Ouvidoria Legislativa no órgão (art. 10, § $3^{\circ}$ da Lei 13.460/2017).

Portanto, uma vez possuidor da informação ou resposta obtida por intermédio do canal de comunicação que é a Ouvidoria, o cidadão está autorizado a usar a deliberação havida dos órgãos internos do Parlamento com o status de informação oficial, ou seja, esse é o posicionamento institucional válido juridicamente, haja vista que ele foi proveniente de uma fonte oficial e segura.

Noutra via, se alguém produz algum comentário que envolva o Parlamento como instituição e divulga nas redes sociais ou em algum blog tomando como base uma informação ou resposta fiel obtida por intermédio da supervisão da Ouvidoria Legislativa, essa notícia não pode ser considerada uma fake new, pois tem lastro em fonte legal com credibilidade e força jurídica.

\subsection{O Papel das Ouvidorias Legislativas na Manutenção da Integridade das Infor- mações e Respostas}

É importante que a informação ou resposta obtida pelo canal da Ouvidoria seja utilizada e divulgada com cautela pelo cidadão que a obteve ou que vai divulgá-la, sempre citando a sua fonte e origem. Qualquer manipulação do conteúdo pode caracterizar uma notícia falsa ou fake new, passando o usuário a responder pelo seu conteúdo ou pela interpretação pessoal que deu à informação obtida.

Para que não haja essa deturpação, de forma a banalizar a informação qualificada, faz-se necessário um posicionamento mais ativo das Ouvidorias Legislativas na sua missão de gestora das informações públicas. Com o advento da recente legislação que conferiu às Ouvidorias Públicas maior atuação, não resta a menor dúvida que será crescente sua atuação mais proativa na instituição além do zelo como gestora da informação².

Nesse sentido, as Ouvidorias Legislativas, sempre que possível, devem adotar as providências necessárias para que a informação ou resposta que elas disponibilizaram ao cidadão seja preser-

\section{Lei 13.460/2017:}

Art. 13. As Ouvidorias terão como atribuições precípuas, sem prejuízo de outras estabelecidas em regulamento especifico:

$[\ldots]$

IV - auxiliar na prevenção e correção dos atos e procedimentos incompatíveis com os princípios estabelecidos nesta Lei;

$[\cdots]$

$\mathrm{VI}$ - receber, analisar e encaminhar às autoridades competentes as manifestações, acompanhando o tratamento e a efetiva conclusão das manifestações de usuário perante órgão ou entidade a que se vincula;

Art. 14. Com vistas à realização de seus objetivos, as Ouvidorias deverão:

I - receber, analisar e responder, por meio de mecanismos proativos e reativos, as manifestações encaminhadas por usuários de serviços públicos. 
vada, identificando eventual manipulação ilícita ou de má-fé que altere o seu conteúdo, e que o cidadão esteja apontando como se fosse da instituição, inclusive promovendo medidas para advertir ou corrigir qualquer distorção dos seus termos.

Como é sabido, há possibilidade de o cidadão utilizar a informação bruta obtida e manuseá-la dentro do conceito de dados abertos, realizando estudos e cruzamentos, mas o produto dessa alteração, ou seja, eventuais interpretações e conclusões obtidas pelo cidadão que o manipula passam a ser vistas como de responsabilidade e titularidade dele e não da instituição de onde obteve os dados.

De modo a cooperar com a integridade das informações que são veiculadas sobre a instituição e seus agentes, os setores administrativos do Parlamento, notadamente o de Comunicação, podem exercer importante parceria no sentido de alertar a Ouvidoria Legislativa, sempre que haja o uso indevido dessas informações, seja nas plataformas digitais e redes sociais, seja nos blogs, rádio, televisão, jornais, entre outros veículos de informação.

Trata-se de uma necessidade essencial: distinguir se uma notícia foi baseada em uma informação ou resposta obtida pelo canal da Ouvidoria ou não. Essa atividade é de fundamental importância para a preservação da imagem do Parlamento e seus integrantes e tende a ser uma prática futura nos debates e discursos dos agentes políticos que o integram.

Por exemplo, quando alguém dispuser de números e estatísticas e citar que os dados foram obtidos através da Ouvidoria ou do Portal da Transparência, a informação obtida nessas condições se constitui importante instrumento para a construção argumentativa e de contestação e empresta credibilidade aos que dela fazem uso.

\subsection{Supervisão das Fake News pelas Ouvidorias Legislativas}

Diversas situações podem ocorrer que desafiam a integridade das informações produzidas e custodiadas em uma instituição pública.

Se um blog, por exemplo, resolve difundir uma notícia que uma Assembleia Legislativa realiza gastos com determinada atividade ou que um deputado federal tem empregado parentes em seu gabinete, não se pode emprestar credibilidade se a informação não tem lastro nos mecanismos de transparência ativa e passiva disponibilizados pela Casa Legislativa, podendo configurar uma fake new.

O Dicionário de Cambridge conceitua fake news como sendo histórias falsas que, ao manterem a aparência de notícias jornalísticas, são disseminadas pela internet (ou por outras mídias), sendo normalmente criadas para influenciar posições políticas, ou ainda como piadas ${ }^{3}$. O impacto das fake news no setor público é preocupante. A desinformação causada pela difusão de notícias falsas prejudica sobretudo a formação do pensamento crítico e a reputação de instituições e agentes públicos.

Outra circunstância bem comum de uso indevido da informação tem sido nos debates políticos ou entrevistas. O uso de estatísticas, percentuais e indicação de montantes financeiros pelos políti-

3 https://dictionary.cambridge.org/pt/dicionario/ingles/fake-news 
cos tem sido uma estratégia bem utilizada de marketing para causar impressão ao telespectador ou para denotar eficiência de uma gestão ou domínio do assunto por um dos interlocutores. Mas o que garante que elas são verdadeiras? As declarações feitas muitas vezes não são confrontadas para saber se se coadunam com a verdade, o que é um desafio para a Justiça Eleitoral e para as Ouvidorias que atuam no setor.

Assim, por exemplo, se dados são divulgados sobre o Congresso Nacional e/ou sobre vereadores, a exemplo de número de faltas, gastos da instituição, votações, valores de contratos administrativos, entre outros temas, sem que haja remissão à fonte legal dessas informações, como é caso do Portal da Transparência, podemos estar diante de uma fake new, e os danos são inevitáveis.

Portanto, é salutar que todos aqueles que vão atuar, tendo como matéria-prima a informação de determinada instituição e seus agentes públicos, sejam instruídos a construir de modo responsável seus argumentos, artigos, estudos, com base nos mecanismos de transparência ativa (Portal de Transparência) ou passiva (Ouvidoria), sob pena de ensejar medidas preventivas e de responsabilidade por ter criado e/ou difundido uma notícia falsa ou fake news.

\subsection{Medidas a Serem Tomadas}

Uma das medidas fundamentais para a prevenção das fake news é conscientizar a sociedade e esclarecê-la sobre o que é uma informação ou resposta oficial, distinguindo-a daquelas que são obtidas à margem da lei de acesso à informação.

Às Ouvidorias do Legislativo e aos demais setores de Comunicação do órgão deve ser mais divulgado o papel fundamental que possuem para essa conscientização, ainda que gradativa, da sociedade, no sentido de que o cidadão possa identificar quando uma notícia é baseada em fontes legais e quando ela foi obtida informalmente.

Éfundamental ressaltarquea Lei deAcessoà Informação prevêexpressamente a responsabilização do cidadão que realiza o uso indevido de informação pessoal obtida e que venha a ferir as liberdades e garantias individuais, a intimidade, a vida privada, a honra e a imagem das pessoas.

Assim sendo, providências importantes, caso seja identificado que a informação ou resposta obtida tenha sido utilizada de forma indevida ou alterada, devem ser tomadas pelas Ouvidorias Legislativas, a exemplo de: (a) esclarecer que aquela informação não é oficial e não vincula a instituição, caso não ratificada; (b) que a parte responsável pela manipulação indevida seja notificada para corri-

gir a informação distorcida; e d) que seja avaliada eventual ação para apuração de responsabilidades pelas Procuradorias Legislativas e Ministério Público.

\section{MANIFESTAÇÕES AGRESSIVAS}

\subsection{Realizadas Perante as Ouvidorias Legislativas}

Uma questão intrigante diz respeito às manifestações que são realizadas perante as Ouvidorias 
Legislativas e o tratamento que deve ser dado àquelas de cunho agressivo, ou seja, que apresentam conteúdo difamatório, calunioso, suscetível de responsabilização tanto na esfera penal como na cível.

De acordo com a definição legal, a calúnia se caracteriza por ser uma imputação falsa de um fato criminoso a alguém. A injúria pode ser qualquer ofensa à dignidade e a difamação representa a imputação de ato ofensivo à reputação de alguém. Outra manifestação realizada que pode ser enquadrada nos tipos penais de crimes contra a honra é o crime de denunciação caluniosa quando se provoca a abertura de processo quando se sabe que o denunciado é inocente ${ }^{4}$.

Estes tipos penais estão previstos no Código Penal e são considerados crimes contra a honra, inclusive podendo ser vítima a pessoa jurídica, mas dependem de representação, queixa-crime de iniciativa do ofendido. Outra fonte importante para o enquadramento de condutas ilícitas e penais é o da Lei 12.965 (Marco Civil da Internet), que pode permitir a identificação do autor da manifestação realizada pelas redes sociais e meios eletrônicos.

Importante mencionar que serão tratadas inicialmente neste capítulo as manifestações previstas na Lei 13.460/2017, quais sejam, as reclamações e denúncias que foram formuladas por usuário identificado ou que pediu restrição de acesso à sua identidade, através do canal da Ouvidoria, seja pelo meio eletrônico (e-mail, formulário) ou físico (correspondência, redução a termo).

As Ouvidorias Legislativas, por lidarem essencialmente com manifestações realizadas pelo público, como reclamações e denúncias contra o Parlamento e seus membros, tem se deparado com provocações que exigem a sua atuação, seja para reafirmar a integridade da fonte segura que representa, seja para avaliar a necessidade de encaminhamento desse tipo de manifestação para a adoção das providências legais.

Tem sido muito comum as reclamações e denúncias agressivas realizadas diretamente aos agentes políticos, muitas vezes em lugares públicos, a exemplo de aeronaves, restaurantes, estádios de futebol, sendo inclusive filmadas e disseminadas nas redes sociais. E se essas práticas se repetirem com o uso do canal da Ouvidoria? O que fazer?

A experiência havida com o pleito eleitoral de 2018 e que continua atualmente a produzir efeitos para as instituições públicas e seus integrantes tem provocado intenso debate sobre eventuais medidas que possam ser tomadas para coibir as agressões direcionadas ao mundo político e que não constituam uso regular do direito à liberdade de expressão ou liberdade de imprensa.

Desse modo, indaga-se se uma manifestação, com conteúdo agressivo, protocolada pelo canal das Ouvidorias Legislativas, pode ser recebida e encaminhada ao setor ou agente público para a resposta prevista em lei. Em outras palavras, uma manifestação desse porte, com ofensas, palavrões, pode ser considerada válida para receber o tratamento previsto na Lei 13.460/2017?

4 Art. 138 - Caluniar alguém, imputando-lhe falsamente fato definido como crime.

Art. 139 - Difamar alguém, imputando-lhe fato ofensivo à sua reputação.

Art. 140 - Injuriar alguém, ofendendo-lhe a dignidade ou o decoro.

Art. 339 - Dar causa à instauração de investigação policial, de processo judicial, instauração de investigação admi-

nistrativa, inquérito civil ou ação de improbidade administrativa contra alguém, imputando-lhe crime de que o sabe inocente:

$\S 1^{\circ}$ - A pena é aumentada de sexta parte, se o agente se serve de anonimato ou de nome suposto. $\S 2^{\circ}$ - A pena é diminuída de metade, se a imputação é de prática de contravenção. 
A questão é importante, uma vez que às Ouvidorias não é dado fazer incursões sobre o mérito do pedido, deixando de remeter uma reclamação ou denúncia por achar descabida ou inadvertida. As Ouvidorias Legislativas realizam um trabalho de filtragem para verificar se a manifestação se refere a atividade desenvolvida pelo Parlamento e seus agentes públicos.

Assim, não tem a Ouvidoria atribuição legal para afirmar se a manifestação é caluniosa ou não, sobremodo quando há tipificação penal específica nesse sentido a ser atribuída por autoridade competente e não lhe cabe examinar se estão presentes os requisitos para a instauração de procedimento criminal contra o usuário.

A despeito das consequências na área penal, não resta dúvida de que uma manifestação que contém em seu bojo um teor agressivo com palavrões, ofensas à reputação e à dignidade de algum agente público ou até mesmo à própria instituição precisa de atenção, pois viola frontalmente o disposto no art. $8^{\circ}$ da Lei $13.460 / 2017^{5}$.

Desse modo, o recebimento de uma manifestação ofensiva não é compatível com o tratamento de respeito que se espera do usuário ao pretender utilizar o canal de comunicação da Ouvidoria. A Carta de Serviços, que é o documento que regula essa relação, deve trazer em seu bojo a advertência de que a violação dos seus termos pelo usuário pode inviabilizar a obtenção de qualquer direito, pois se não se manifesta com urbanidade não se pode receber resposta da mesma maneira.

A nosso sentir, uma sugestão de procedimento para as Ouvidorias Legislativas, em circunstâncias vexatórias e que não fere os princípios da Lei 13.460/2017, seria devolver a manifestação para que o usuário tenha ciência das consequências que poderão Ihe ser imputadas, solicitando uma retificação ou ratificação do conteúdo, caso deseje prosseguir assumindo os riscos de sua demanda.

As advertências são necessárias uma vez que tem sido prática muito comum a instauração de processos ou procedimentos contra agentes políticos, especialmente no período pré-eleitoral, para criar um fato eleitoral ou uma notícia que venha a prejudicar a reputação do candidato, propósito para o qual não pode o canal de Ouvidoria servir como instrumento.

Sem embargo, caso não retificado o seu conteúdo, não resta alternativa senão a Ouvidoria enviar a manifestação para uma possível resposta do que pode ser aproveitado dessa manifestação, dando ciência às Procuradorias Legislativas ou a(às) assessoria(s) do(s) agente(s) político(s) envolvido(s) para que avaliem a necessidade de tomar as devidas medidas judiciais cabíveis contra o usuário ofensor.

\subsection{Realizadas Perante as Redes Sociais}

Uma questão também delicada diz respeito às manifestações agressivas quando realizadas perante as redes sociais. No Facebook, por exemplo, tem sido comum a veiculação de comentários ofensivos quando é publicada alguma notícia ou atividade do Parlamento em suas páginas oficiais eletrônicas.

\footnotetext{
5 Art. $8^{\circ}$ São deveres do usuário:

I- utilizar

adequadamente os serviços, procedendo com urbanidade e boa-fé; [...]
} 
Há Ouvidorias que ainda não adotaram as redes sociais como ferramenta de comunicação para o recebimento de manifestações do cidadão à luz da Lei 13.460/2017, embora seja uma tendência para o futuro. Enquanto isso não ocorre, as manifestações, apesar de representarem uma reclamação ou denúncia em potencial, não podem ser encaminhadas pelas Ouvidorias Legislativas para os procedimentos internos de resposta, mas sim pelos setores de Comunicação do órgão que gerenciam as redes sociais.

Assim, compete aos setores de Comunicação dos Parlamentos desenvolverem sistema ou programa de resposta imediata e/ou esclarecimento dos fatos em espaço na própria rede social, realizando as devidas advertências e podendo até indicar o canal da Ouvidoria para que o usuário possa optar por esse meio, se quiser uma resposta formal da instituição.

Esse tipo de atuação é fundamental, pois o uso das redes sociais para espalhar denúncias ou reclamações, sem uma fonte legal válida, se avoluma a cada dia na internet, e a rápida intervenção previne a disseminação das fake news e a prática de crimes cibernéticos.

Caso as manifestações tenham conteúdo ofensivo, há necessidade de que seja alertado o usuário infrator sobre possíveis consequências de ordem penal e civil. Caso mantido e difundido o comentário agressivo, o setor de Comunicação deve remeter a situação ao crivo das Procuradorias Legislativas, a fim de investigar a possibilidade de crime cibernético com fundamento no Marco Civil da Internet (Lei Federal 12.965/2014).

Em diversas ocasiões algumas Procuradorias do Legislativo já foram instadas a atuar nesse sentido solicitando a retirada das postagens ofensivas nas redes sociais contra a instituição que elas representam, assim como sugerindo aos agentes públicos atingidos a propositura de queixa crime/ação penal, tendo o Judiciário já se manifestado em diversas ocasiões favoravelmente aos direitos de personalidade em oposição ao direito de liberdade de expressão/imprensa.

\subsection{Realizadas Perante a Mídia}

Muitas manifestações sob a forma de reclamação e denúncia contra o Parlamento e seus membros podem surgir também na mídia tradicional, a exemplo de jornais, rádio e TV e através de blogs jornalísticos. Quando exercidas de forma regular, elas representam legítimo exercício da liberdade de expressão e/ou liberdade de imprensa.

Em alguns jornais, por exemplo, disponibiliza-se um espaço para dar voz ao leitor e muitas vezes surgem manifestações que representariam, em potencial, uma reclamação ou denúncia, à luz do Código de Defesa do Usuário do Serviço Público. Do mesmo modo, uma matéria realizada em um blog contendo uma denúncia contra um deputado estadual ou uma reclamação contra o Senado em uma entrevista na rádio devem ser examinadas com atenção.

Em que pese não terem sido formuladas nos moldes previstos pela Lei 13.460/2017 para que haja uma resposta oficial, isso não significa que elas devem ser desprezadas. As manifestações realizadas à margem do canal da Ouvidoria não têm o condão de instaurar o rito previsto em lei, entretanto devem ser monitoradas pelos setores que atuam sobre a gestão de informação, que podem dialogar a respeito e verificar quais providências podem ser tomadas. 
É fundamental que essas manifestações não sejam desconsideradas de plano, até porque podem ser um sinalizador de uma denúncia consistente, mas por outro lado podem atingir a imagem do Parlamento e seus membros, devendo sempre que possível serem respondidas de maneira adequada e rápida para que o contraditório seja exercido diante de uma crítica ou denúncia infundada, prevenindo a disseminação de uma fake new.

Todavia é importante sopesar que há muitos blogs e sites na internet que procuram, na realidade, visibilidade e número de acessos com notícias escandalosas para que venham a se tornar celebridades no mundo cibernético, devendo ser avaliado até que ponto é necessário, ao responder, dar alguma credibilidade a quem está atuando de má-fé.

Do mesmo modo que nas redes sociais, se há excesso ou abuso da liberdade de expressão e/ ou de imprensa, há necessidade de adoção dos mesmos mecanismos de prevenção previstos para o uso ofensivo nas redes sociais, com remessa da manifestação agressiva para as Procuradorias Legislativas para que as medidas judiciais sejam adotadas, garantindo-se o direito de resposta e a punição de eventual crime praticado contra a honra.

\subsection{Realizadas Através do Anonimato}

A reclamação e/ou denúncia identificada se distingue da chamada comunicação de irregularidade, que tem sido tipificada como aquela mensagem encaminhada às Ouvidorias comunicando a existência de uma ilegalidade ou irregularidade, com ou sem evidências, mas em que não há identificação do autor da manifestação.

Enquanto na denúncia identificada há o dever de serem apreciados os seus termos pelo Parlamento através dos órgãos competentes, a comunicação de irregularidade, apesar de também merecer ser analisada, será tratada de maneira discricionária. Ela será considerada dentro de um contexto com outros indícios e provas, mas diferentemente da denúncia identificada, não há obrigatoriedade de resposta no prazo legal, nem obviamente ciência das decisões adotadas ao denunciante anônimo.

A "denúncia anônima", como é popularmente conhecida, será avaliada pelos setores administrativos do Legislativo para que realizem uma investigação preliminar sobre o seu aproveitamento ou a instauração de eventual processo que apure o que foi apontado. Essa prática já era adotada por muitas Casas Legislativas, antes mesmo da Lei 13.460/2017, a exemplo dos trabalhos das Comissões Parlamentares de Inquérito, quando era muito comum o recebimento de denúncias anônimas, as quais ajudavam nos trabalhos investigativos.

Mas o que acontece se a comunicação de irregularidade ou "denúncia anônima" é realizada através do canal da Ouvidoria pelo meio eletrônico ou divulgada nas redes sociais, contendo ofensa a alguém ou à instituição, configurando-se assim crime contra a honra?

Graças ao avanço da tecnologia, o anonimato eletrônico vem sofrendo intenso combate, e a ideia que ganha força é a de que não haveria possibilidade prática de divulgação de conteúdo anônimo na internet, vez que todos os acessos feitos na rede são passíveis de gerar a locação do responsável por meio dos IPs. Ainda que determinado conteúdo não esteja assinado, seu autor seria sempre identificável. 
Portanto, em que pese a Lei 12.965/2014 (Marco Civil da Internet) ter estimulado a diversidade de opiniões e liberdade de crítica na internet (art. $2^{\circ}$, caput) os atos ilícitos praticados no ambiente da internet não são diferentes daqueles que ocorrem no mundo real, razão pela qual seus autores podem ser penalizados civil e criminalmente (art. $7^{\circ}$, I da Lei $12.965 / 2014$ ).

$\mathrm{Na}$ área eleitoral, o artigo 57-D, caput, da Lei n 9.504/97, prescreve que é "vedado o anonimato durante a campanha eleitoral, por meio da rede mundial de computadores - internet, assegurado o direito de resposta (...)". De acordo com o $\S 2^{\circ}$ desse mesmo artigo, sua violação sujeita o responsável à multa no valor de $\mathrm{R} \$ 5$ mil a $\mathrm{R} \$ 30$ mil.

Na própria tipificação do crime de denunciação caluniosa, o cometimento do ato através do anonimato representa um aumento da pena. Há possibilidade de tipificação penal também quando há a realização de "trote" através do telefone que é disponibilizado ao cidadão pela Ouvidoria.

Logo, apesar de uma comunicação de irregularidade ser considerada para o propósito de estimular a participação e o controle social, o anonimato não pode ser utilizado como escudo para que crimes sejam perpetrados nos meios eletrônicos e redes sociais, disseminando ofensas, pelo que, ocorrendo essa hipótese, tanto a Ouvidoria como o setor de Comunicação podem encaminhar esse tipo manifestação para a Procuradoria do Legislativo, que, em razão de ordem judicial, pode obter dos provedores de conexão e de acesso a aplicações da internet os registros de conexão, além de outras informações que possam contribuir para identificação do usuário ou do terminal.

Em que pesem as limitações e alterações que serão trazidas pela Lei Geral de Proteção de Dados Pessoais (Lei 13.709/2018) quanto ao acesso e tratamento dos dados pessoais nos meios eletrônicos, isso não significa que através de ordem judicial, com a atribuição de sigilo nos autos, essas práticas criminosas não possam ser apuradas ${ }^{6}$.

\section{CONSIDERAÇÕES FINAIS}

É inegável que já podem existir fábricas de criação de notícias falsas espalhadas pelo mundo, dentro de uma cadeia de conexões cujo objetivo é viralizar aquela notícia para que ela produza os efeitos desejados pelos seus mentores. Devido ao volume de fake news existentes, muitas vezes produzidas para se difundir um só argumento, sem oportunidade para o contraditório, a busca de fontes confiáveis se torna uma grande necessidade na via pública, sobretudo no ambiente político.

Mas qual seria uma fonte confiável para se questionar o Poder Legislativo e seus membros? Sem dúvida, a resposta é a seguinte: a informação que foi obtida nos Portais de Transparência e/ou aquela obtida por intermédio do canal de comunicação disponibilizado pelas Ouvidorias Legislativas.

Essas fontes, desde que utilizadas adequadamente pelo usuário, apresentam um status que merece ser acreditado, pelo que a utilização dos canais de transparência ativa e passiva deve ser

6 Art. 11. O tratamento de dados pessoais sensíveis somente poderá ocorrer nas seguintes hipóteses:

[...]

II - sem fornecimento de consentimento do titular, nas hipóteses em que for indispensável para: [...]

d) exercício regular de direitos, inclusive em contrato e em processo judicial, administrativo e arbitral, este último nos termos da Lei n 9.307, de 23 de setembro de 1996 (Lei de Arbitragem); [...] 
uma tendência cada dia maior para que a sociedade saiba distinguir uma informação oficial daquela obtida à margem da lei.

Nessa linha de entendimento, faz-se necessário educar as pessoas para que busquem mais essa via de distinção, pelo que os gestores administrativos precisam adotar como prioritária essa nova modalidade de comunicação com a Administração Pública para que as informações produzidas e custodiadas naquele órgão não sofram vazamentos inadequados e manipulação indevida, o que somente vai ocorrer com o fortalecimento do trabalho realizado pelas Ouvidorias Legislativas.

Tanto devem ser combatidas as fake news, com a remissão a uma fonte segura como é a do rito monitorado pela Ouvidoria, como as agressões virtuais ou crimes cibernéticos que podem ser direcionados contra o Parlamento e seus membros, devendo a Ouvidoria atuar na sua prevenção e combate, uma vez que, de acordo com o Código de Defesa do Usuário do Serviço Público, o direito de realizar uma manifestação e obter uma resposta, apesar de amplo e protegido pela legislação vigente, com esteio na liberdade de expressão, liberdade de crítica e liberdade de imprensa, obedece a limites de urbanidade, ética e respeito.

Se essas cláusulas constitucionais não são respeitadas com o uso moderado e razoável das manifestações, não resta dúvida de que as ofensas praticadas devem ser combatidas e penalizadas, pelo que as Ouvidorias Legislativas exercem papel de liderança na identificação dessas ofensas. $O$ que não significa dizer que elas estão impedindo a manifestação dos usuários, mas sim conferindo seriedade a esse tipo de atividade para que ela possa produzir os efeitos esperados pelo cidadão.

\section{REFERÊNCIAS}

BRASIL. Lei Federal 13.460 de 26 de junho de 2017. Código de Defesa do Usuário de Serviço Público. Lei Federal 9.504 de 30 de setembro de 1997. . Decreto-lei 2.848 de 7 de dezembro de 1940, que criou o Código Penal Brasileiro. . Lei Federal 12.527 de 18 de novembro de 2011. Lei de Acesso à Informação (LAI). Lei Federal de 14 de agosto de 2018. Lei Geral de Proteção de Dados Pessoais. Lei Federal 12.965 de 23 de abril de 2014. Marco Civil da Internet. 